\title{
FATIGUE LIFE ASSESSMENT OF INCLINED WELDED JOINTS IN STEEL BRIDGES SUBJECTED TO COMBINED NORMAL AND SHEAR STRESSES
}

\author{
Z.Y. Jie ${ }^{1, *}$, Y.D. Li $^{2}$, X. Wei ${ }^{2}$ and P. Zhuge ${ }^{1}$ \\ ${ }^{1}$ Faculty of Architectural, Civil Engineering and Environment, Ningbo University, Ningbo 315211, China \\ ${ }_{2}^{2}$ School of Civil Engineering, Southwest Jiaotong University, Chengdu 610031, China \\ *(Corresponding author: Email: jiezhiyu_8@163.com)
}

Received: 22 December 2016; Revised: 12 July 2017; Accepted: 12 December 2017

\begin{abstract}
The paper presents fatigue life assessment of inclined welded joints with a new geometric configuration in steel bridges. Fatigue tests on full penetration load-carrying fillet cruciform welded joints with inclination angles of $0^{\circ}, 15^{\circ}, 30^{\circ}$, and $45^{\circ}$ subjected to uniaxial cyclic loading are performed. Hot spot normal and shear stress ranges are obtained by a linear extrapolation, and a sensitivity analysis is carried out to determine the appropriate mesh size. The fatigue life results predicted by the equivalent stress range method, DNV(Det Norske Veritas), Eurocode 3, and IIW(the International Institute of Welding) are compared with test results. The results show that the fatigue cracks in all of the specimens initiate at the weld toe but propagate in different directions. There are two cracking types: (a) cracking along the weld $\left(\theta=0^{\circ}, 15^{\circ}\right)$; (b) cracking perpendicular to the direction of the applied load $\left(\theta=30^{\circ}, 45^{\circ}\right)$. The fatigue life increases with an increase in the inclined angle due to a decrease in the normal stress range perpendicular to the weld. The fatigue life tends to be overpredicted by Eurocode 3 at the large inclination angle. The FAT90 used by DNV is more conservative than the FAT100 recommended by Eurocode 3 and IIW, so that the fatigue life is underestimated. It is concluded that the equivalent stress range method and IIW are in good agreement with the fatigue test results. The equivalent stress range method is more suitable to assess the fatigue life of inclined welded joints subjected to combined normal and shear stresses due to the ease of implementation and low computational cost. The fatigue design curve of FAT100 is recommended for the equivalent stress range method.
\end{abstract}

Keywords: Welded joint, steel bridge, inclined angle, fatigue life assessment, hot spot stress

DOI: $10.18057 /$ IJASC.2018.14.6

\section{INTRODUCTION}

Steel bridges have been widely used in long-span bridges due to their light weight, high strength, short installation time and relatively low monetary costs. There are a large number of welded joints (butt joints, $\mathrm{T}$ joints, cruciform joints, etc.) in steel bridges. The weld toes and roots can create high stress concentrations due to the geometric discontinuity. Consequently, fatigue cracks are more likely to appear in weld toes and roots rather than in the base metal subjected to repeated loadings [1]. During crack propagation, when a crack size reaches a critical value, welded joints suddenly fracture due to a reduction in the cross-sectional area and consequently the inability to resist further loading. Therefore, specific design guidelines are needed to avoid fatigue failures of welded joints in steel bridges during service life [2].

Three approaches are commonly employed for fatigue assessment of welded joints. The nominal stress approach is usually used for simple welded joints and loadings where nominal stresses can clearly be determined. Most fatigue design specifications use nominal stresses to assess the fatigue life of welded details according to different nominal stress design curves. This method cannot be applied in complex welded joints and loadings, but the hot spot stress approach can be used for this situation [3]. The hot spot stress approach was initially developed for fatigue assessment of offshore tubular joints [4]. Now, this approach is applied to welded plate structures and included in fatigue design specifications, such as Eurocode 3 [5], IIW(the International Institute of Welding) 
[6], and DNV(Det Norske Veritas) [7]. There are five methods for determining the hot spot stress in the literature, including surface extrapolation, one point stress method, through thickness method, the Dong method, and $1 \mathrm{~mm}$ method [6, 8-10]. Many studies have been conducted to improve the accuracy of the hot spot stress estimation in three aspects: mesh density [11], element type [12], and computational method [13]. The local stress at the weld root cannot be described in detail by nominal and hot spot stresses [14]. The notch stress approach [15-17] used the maximum elastic notch stress at the weld toe or root for fatigue analysis. However, this approach requires more modelling and analysis work for the numerical simulation of complex welded structures.

There are many welded details in a steel bridge subjected to combined tension and shear stresses, such as welded rib-diaphragm connections in steel orthotropic decks [18] and welds that join corrugated plates to flange plates [19]. In these welded details, the crack initiation sites of the weld toe are in multiaxial stress states. The multiaxial fatigue damage mechanism is different from that of the uniaxial fatigue counterpart. Many methods are proposed for multiaxial fatigue assessment of welded structures. These approaches are applied in nominal stress, hot spot stress, and local stress concepts. These methods include principal stress or Von Mises stress methods, the interaction equation method in Eurocode 3 and IIW, and the modified Wöhler curve method [20]. The fatigue life based on conventional fatigue design methods has been under- or overestimated when combined normal and shear stresses were applied in phase simultaneously, so an equivalent stress range method has been proposed in [21]. The interaction equations from Eurocode 3, IIW, and DNV for calculating effective stress ranges based on the normal and shear stress ranges perpendicular and parallel to the weld respectively have been used to assess fatigue strength [22]. Bäckström [23] used the interaction equations from SFS 2378 [24], Eurocode 3, and IIW to evaluate the fatigue life. It is found in [23] that the fatigue life estimated using IIW is more closely in accordance with the experimental result. Kainuma et al. [25] clarified that the effect of the inclined angle on fatigue strength was small for welded specimens. Jen et al. [26] studied the effect of oblique loading on fatigue strength of butt-welded structures and found that the normal stress parallel to the loading direction played a significant role in the fatigue strength design and critical crack locations, which were identical to those experiencing the maximum Von Mises stress. Susmel [27] proposed the modified Wöhler curve method for estimating fatigue strength of inclined welded connections. The fatigue life assessment process based on the modified Wöhler curve method is complex and difficult to use in practice. The accuracy of fatigue life prediction results is extremely dependent on the use of reference fatigue curves in the specification, and the choice of fatigue design curves for complex welded joints remains a challenging and unsolved issue [28]. The main aim of this study is to determine a convenient method and an appropriate fatigue design curve for fatigue life estimation of inclined welded joints.

According to the statement above, full penetration load-carrying fillet cruciform welded joints largely used in steel bridges are taken as research objects, and $0^{\circ}, 15^{\circ}, 30^{\circ}$, and $45^{\circ}$ weld inclined angles are constructed to simulate different complex stress states. To date, fatigue life assessment of these new welded joints has not been investigated. Consequently, it is necessary to carry out an in-depth study. Fatigue tests on cruciform welded joints with full penetration load-carrying welds inclined to the direction of the uniaxial cyclic loading are performed. Due to this complex geometry, it is difficult to estimate the nominal stress of a cross section. Welded joints are directly modelled by normal and shear stresses perpendicular and parallel to the weld from a multiaxial fatigue point of view, respectively. Thus, the hot spot stress approach is applied to obtain hot spot the normal stress range and shear stress range by a linear extrapolation method based on a numerical analysis. A sensitivity analysis is carried out for determining the appropriate mesh size. Fatigue life assessment is conducted by the equivalent stress range method, DNV, Eurocode 3, and IIW. Finally, the fatigue design curves and appropriate fatigue life evaluation methods for inclined welded joints in steel bridges subjected combined normal and shear stresses are determined. 


\section{FATIGUE TEST}

The crack initiation locations of the welded joints with inclined welds are in multiaxial stress states subjected to uniaxial cyclic loading. The nominal stress range can be decomposed into the normal stress range $\Delta \sigma_{x}$ and the shear stress range $\Delta \tau_{x y}$ perpendicular and parallel to the weld from a multiaxial fatigue point of view, respectively (Figure 1) [27]. They can be expressed as

$\Delta \sigma_{x}=\Delta \sigma_{\text {nom }} \cdot \cos ^{2} \theta$

$\Delta \tau_{x y}=\Delta \sigma_{\text {nom }} \cdot \sin \theta \cdot \cos \theta$

where $\Delta \sigma_{\text {nom }}$ is the nominal stress range, and $\theta$ is the angle between the weld and the direction perpendicular to the applied load.

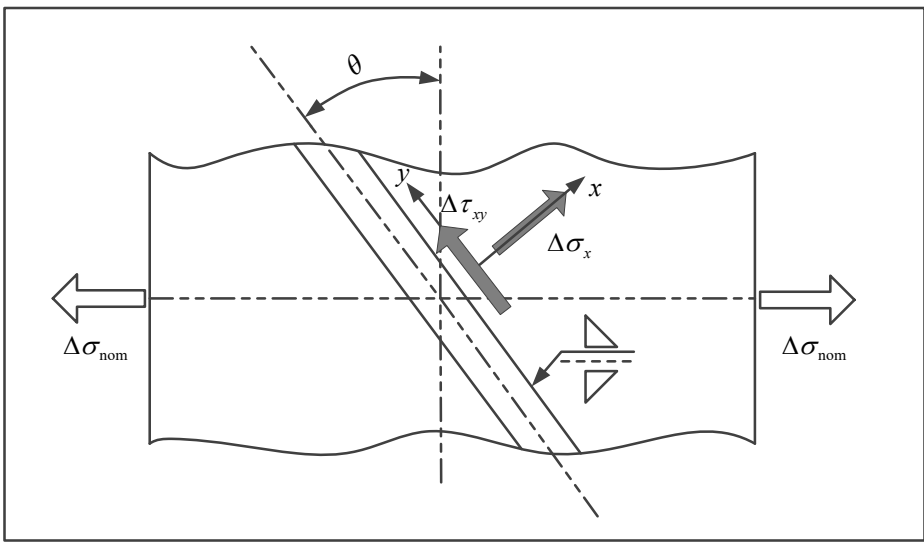

Figure 1. Inclined Fillet Weld subjected to Uniaxial Fatigue Loading

\subsection{Specimens and Loading}

The cruciform welded joints with different inclined angles were machined by Q345qC steel [29]. The chemical composition of Q345qC steel consisted of $\mathrm{C}(0.17 \%), \mathrm{Si}(0.27 \%), \mathrm{Mn}(1.43 \%), \mathrm{P}, \mathrm{S}, \mathrm{V}$, $\mathrm{Cr}$, Mo, and Ni. The yield and tensile strength were $360 \mathrm{MPa}$ and $575 \mathrm{MPa}$, respectively, and the elongation was $28 \%$.

Fatigue tests were performed on a servo-hydraulic machine under a sine wave axial cyclic load. According to the maximum force of the machine and the specimen size, a uniform axial tensile stress range of $160 \mathrm{MPa}$ was applied at one end of the plate. The maximum and minimum fatigue loads were $P_{\max }=142.2 \mathrm{kN}$ and $P_{\min }=14.2 \mathrm{kN}$, respectively. The testing frequency was between 5 and $10 \mathrm{~Hz}$ depending on the load level and rigidity, and the load ratio $R\left(R=P_{\min } / P_{\max }\right)$ was 0.1 . Three identical specimens were tested under the same stress range due to the scatter in the fatigue test results. The dimensional parameters of the cruciform welded joints were listed in Table 1. The geometric configurations of the cruciform welded joints and fatigue specimen loading were illustrated in Figures 2-3. 
Table 1. Dimensional Parameters of the Cruciform Welded Joints

\begin{tabular}{cccc}
\hline Specimen Number & Inclined angle & Stress range(MPa) & Length $b(\mathrm{~mm})$ \\
\hline D1S2 & $0^{\circ}$ & 160 & 92.0 \\
D2S2 & $15^{\circ}$ & 160 & 85.3 \\
D3S2 & $30^{\circ}$ & 160 & 77.6 \\
D4S2 & $45^{\circ}$ & 160 & 67.0 \\
\hline
\end{tabular}

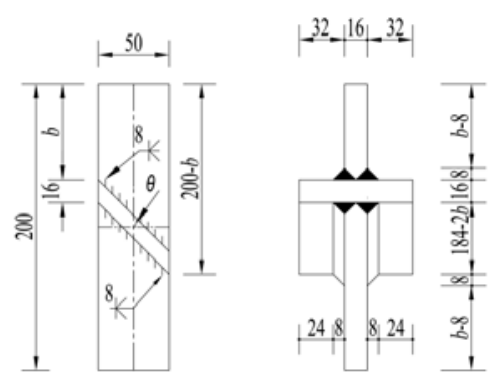

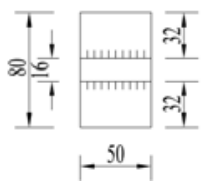

Figure 2. Geometric Configurations of the Cruciform Welded joints

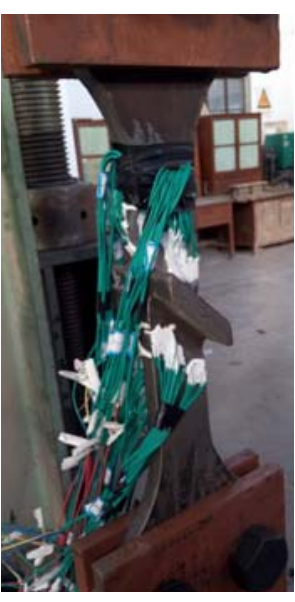

Figure 3. Fatigue Specimen Loading

\section{$2.2 \quad$ Test Results}

The number of cycles was recorded once a macroscopic crack was found, and the crack propagation was observed by a magnifier. The fatigue life was determined when the first through-thickness crack was founded. The fatigue life test results of the cruciform welded joints with different inclination angles were listed in Table 2.

Table 2. Fatigue Life Test Results of the Cruciform Welded Joints with different Inclination Angles

\begin{tabular}{cccc}
\hline Specimen Number & Inclined angle & Stress range(MPa) & Fatigue life(cycles) \\
\hline D1S2 & $0^{\circ}$ & 160 & $4.11 \times 10^{5}$ \\
D2S2 & $15^{\circ}$ & 160 & $5.16 \times 10^{5}$ \\
D3S2 & $30^{\circ}$ & 160 & $6.27 \times 10^{5}$ \\
D4S2 & $45^{\circ}$ & 160 & $9.77 \times 10^{5}$ \\
\hline
\end{tabular}

The fatigue cracks in all of the specimens were initiated at the weld toe, where the stress concentration was higher than others, but propagated in different directions. There were two cracking types: (a) cracking along the weld; (b) cracking perpendicular to the direction of applied load (Figure 4). The cracks propagated along the weld when the weld inclined angle was $0^{\circ}$ or $15^{\circ}$. However, the cracks propagated along the perpendicular direction of the applied load for $30^{\circ}$ and $45^{\circ}$ inclined angles. The main reason for this phenomenon was that with an increase in the inclined 
angle, the weld length and the shear stress parallel to the weld and rigidity increased, but the normal stress perpendicular to the weld decreased. The crack propagation was perpendicular to the direction of the maximum principal stress [30]. The direction of the maximum principal stress was perpendicular to the weld when the inclined angle was small. However, the direction of the maximum principal stress was parallel to the direction of the applied load when the inclined angle was relatively large.

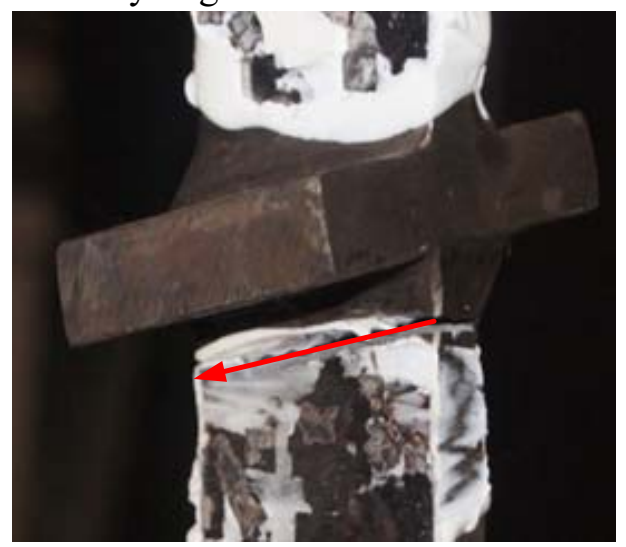

(a) Type a

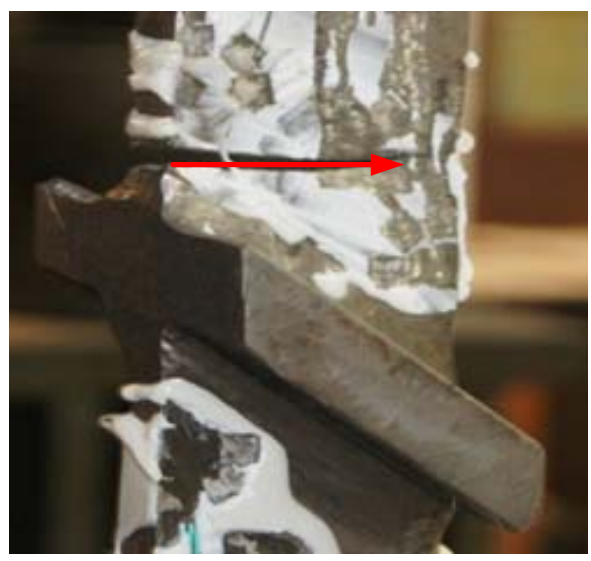

(b) Type b

Figure 4. Fatigue Crack Propagation

The fatigue fracture morphology of the specimens can be divided into two regions: (1) the smooth region of fatigue crack initiation and propagation; (2) the rough region of brittle fracture (Figure 5). The fatigue crack was initiated from the bottom left corner under cyclic loading and then gradually propagated. The crack surface became smooth due to repeated friction, and a quarter elliptic crack growth trajectory was formed. When the strength of material cannot resist external loads due to a reduction in the effective cross section, the specimens suddenly ruptured.

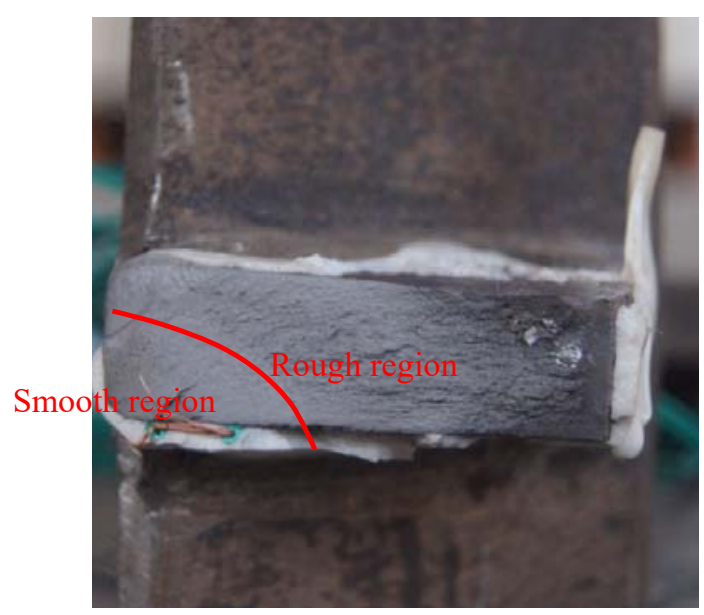

Figure 5. Fatigue Fracture Morphology

\section{FINITE ELEMENT MODELLING}

\subsection{The Hot Spot Stress Approach}

The term 'hot spot' refers to the critical point in a structure where fatigue cracking can be expected to occur due to a discontinuity or a notch [31]. The hot spot is usually located at the weld toe in 
welded structures. The hot spot stress $\sigma_{\mathrm{hs}}$ is the value of the stress at the hot spot but excludes the local nonlinear stress peak produced by the weld shape or the notch. This value can be obtained by a linear elasticity formulas or a finite element method. The hot spot stress is composed of the membrane stress $\sigma_{\mathrm{m}}$ and the bending stress $\sigma_{\mathrm{b}}$ (Figure 6).

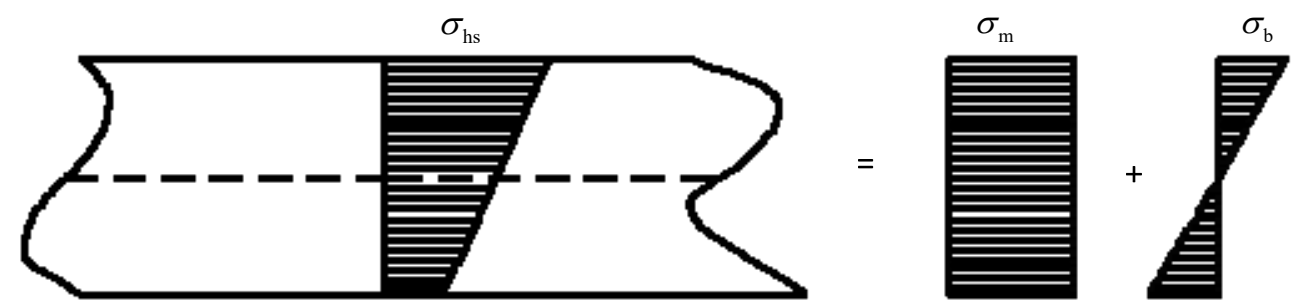

Figure 6. The Composition of the Hot Spot Stress

Two types of hot spots are defined according to their location on the plate and their orientation to the weld toe, as defined in Figure 7 according to IIW. Different methods are used to evaluate the hot spot stress for each type of weld toe. It can be seen that the fatigue failures of weld toes belong to the Type "a" hot spot according to test results. Due to its relative ease of use, a surface extrapolation method is widely used in fatigue assessment and can be divided into linear and quadratic extrapolations. It is found that there is no significant difference between linear and quadratic extrapolations in evaluating the hot spot stress [12]. The element type and mesh size of the finite element model also affect the results. A 3D solid model including the weld is recommended for simulating complex welded structures according to IIW. When a fine mesh with an element length not more than $0.4 t$ at the Type "a" hot spot is used, the linear extrapolation equation using nodal stresses at two reference points $0.4 t$ and $1.0 t$ from the weld toe is provided below, where $t$ is the main plate thickness (Figure 8(a)).

$\sigma_{\mathrm{hs}}=1.67 \sigma_{0.4 \mathrm{t}}-0.67 \sigma_{1.0 \mathrm{t}}$

However, DNV recommends that the extrapolation reference points should be located at distances of $0.5 t$ and $1.5 t$ from the weld toe (Figure $8(\mathrm{~b})$ ). Similarly, the hot spot stress can be expressed as

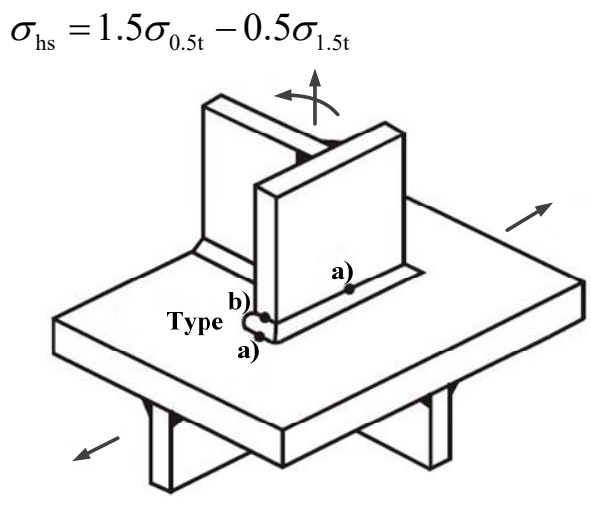

Figure 7. Types of Hot Spots

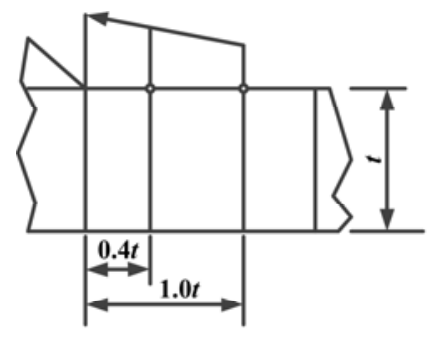

(a) IIW

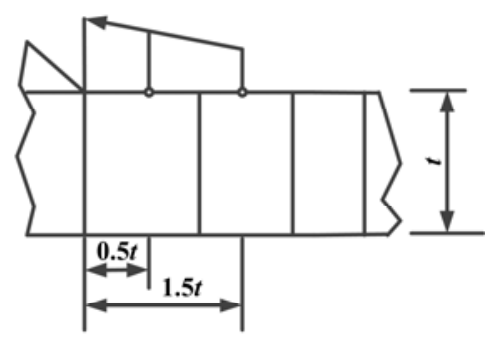

(b) DNV

Figure 8. The Linear Extrapolation of Hot Spot Stress

\subsection{Calculation of the Hot Spot Stress}

According to the discussion above, the linear extrapolation is used to calculate the hot spot stress by a finite element analysis. Finite element models for cruciform welded joints with $0^{\circ}, 15^{\circ}, 30^{\circ}$, and $45^{\circ}$ inclined angles are created using the commercial finite element software ANSYS [32]. The 8-node solid element (SOLID45) is selected to simulate these models, and the weld shape is 
simplified as an isosceles right triangle. A uniform axial tensile stress of $160 \mathrm{MPa}$ is applied at one end of the plate, and a fixed constraint is applied at the other end of the plate. According to the symmetry, only one-half finite element model is considered, and the symmetric constraints are applied to the nodes of the symmetric surface (Figure 9). Young's modulus $E$ and Poisson's ratio $v$ are $2.1 \times 10^{5} \mathrm{MPa}$ and 0.3 , respectively. However, the mesh size has an important effect on the hot spot stress. Therefore, the appropriate mesh size should be determined using a sensitivity analysis. Three different mesh sizes are provided below by the recommendations of IIW. The element numbers at a distance $1.5 t$ from weld toe are 5, 15, and 30 . The element numbers along the weld are 10, 20, and 40. The number of elements along the thickness is 4 . These mesh sizes are represented by MS1 $(5 \times 10)$, MS2 $(15 \times 20)$, and MS3 $(30 \times 40)$. Hot spot stress ranges based on the linear extrapolation method at different inclined angles and mesh sizes are shown in Table 3.

Table 3. Hot Spot Stress Ranges under Different Inclined Angles and Mesh Sizes(MPa)

\begin{tabular}{|c|c|c|c|c|c|c|c|}
\hline \multirow{2}{*}{$\begin{array}{l}\text { Inclined } \\
\text { angle }\end{array}$} & \multirow{2}{*}{$\begin{array}{l}\text { Mesh } \\
\text { size }\end{array}$} & \multirow{2}{*}{$\begin{array}{c}\text { Normal } \\
\text { stress range }\end{array}$} & \multirow{2}{*}{$\begin{array}{l}\text { Shear stress } \\
\text { range }\end{array}$} & \multicolumn{2}{|c|}{ Hot spot normal stress range } & \multicolumn{2}{|c|}{ Hot spot shear stress range } \\
\hline & & & & IIW & DNV & IIW & DNV \\
\hline \multirow{3}{*}{$0^{\circ}$} & MS1 & & & 188.33 & 169.14 & & \\
\hline & MS2 & 160.00 & - & 165.89 & 160.99 & - & - \\
\hline & MS3 & & & 165.96 & 161.06 & & \\
\hline \multirow{3}{*}{$15^{\circ}$} & MS1 & & & 178.16 & 159.32 & 46.86 & 43.11 \\
\hline & MS2 & 149.28 & 40.00 & 156.54 & 151.13 & 44.62 & 43.25 \\
\hline & MS3 & & & 156.44 & 151.16 & 44.77 & 43.38 \\
\hline \multirow{3}{*}{$30^{\circ}$} & MS1 & & & 145.69 & 130.71 & 79.85 & 75.27 \\
\hline & MS2 & 120.00 & 69.28 & 130.99 & 123.72 & 76.59 & 73.76 \\
\hline & MS3 & & & 130.17 & 123.42 & 76.48 & 73.68 \\
\hline \multirow{3}{*}{$45^{\circ}$} & MS1 & & & 107.19 & 94.92 & 98.29 & 90.01 \\
\hline & MS2 & 80.00 & 80.00 & 95.45 & 89.38 & 91.43 & 87.46 \\
\hline & MS3 & & & 95.28 & 89.41 & 91.22 & 87.50 \\
\hline
\end{tabular}

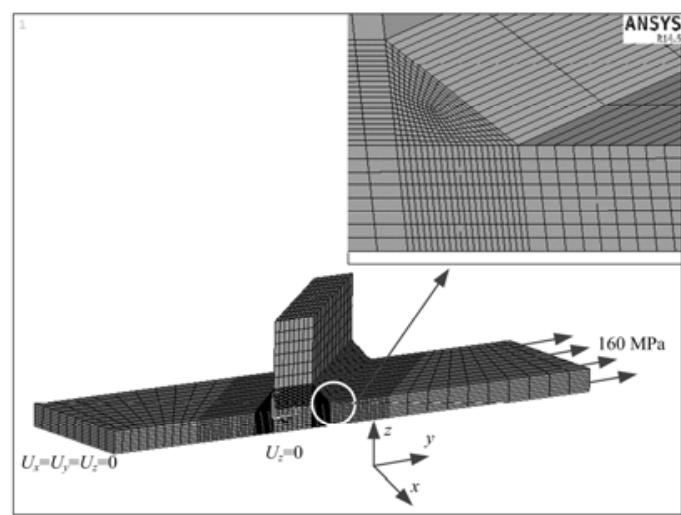

Figure 9. One-half Finite Element Model 
It can be seen from Table 3 that with an increase in the inclined angle, the hot spot normal stress range decreases, while the hot spot shear stress range increases. Additionally, the hot spot stress range increases with an increase in the mesh size. The hot spot stress range calculated by the linear extrapolation rule of DNV is slightly lower than that of IIW. The difference in the hot spot stress ranges for various mesh sizes caused by DNV is small but relatively large by IIW. The maximum relative errors are $6.2 \%$ and $13.9 \%$ for DNV and IIW, respectively. The main reason is that the distance from the weld toe is farther, and hot spot stress is smaller. When the minimum mesh size is less than $0.1 t$, the effect of the mesh size on the hot spot stress range is very small. Finally, MS2 is recommended to calculate the hot spot stress range considering the accuracy and computational efficiency.

\section{FATIGUE LIFE ASSESSMENT}

Kim and Yamada [33] recommended the equivalent stress range $\Delta \sigma_{\text {eqv }}$ to evaluate the fatigue life of inclined fillet welded joints by the following equation

$$
\Delta \sigma_{\mathrm{eqv}}=\Delta \sigma_{\mathrm{nom}} \cdot \cos \theta=\sqrt{\Delta \sigma_{x}^{2}+\Delta \tau_{x y}^{2}}
$$

According to DNV, the effective stress range $\Delta \sigma_{\text {eff }}$ considering the normal stress range $\Delta \sigma_{x}$ and the shear stress range $\Delta \tau_{x y}$ can be expressed in the following form

$$
\Delta \sigma_{\text {eff }}=\sqrt{\Delta \sigma_{x}^{2}+\beta \Delta \tau_{x y}^{2}}
$$

The $S$ - $N$ category $\mathrm{C} 2$ may be used for the continuous shear stress in a full penetration weld [34]. The effective hot spot stress range combined with the hot spot $S-N$ curve $\mathrm{D}$ is derived as

$$
\Delta \sigma_{\text {eff }}=\max \left\{\begin{array}{l}
\sqrt{\Delta \sigma_{x}^{2}+0.81 \Delta \tau_{x y}^{2}} \\
\alpha \Delta \sigma_{1} \\
\alpha\left|\Delta \sigma_{2}\right|
\end{array}\right.
$$

where $\alpha=0.90$ if the detail is classified as $\mathrm{C} 2$ with stress parallel to the weld at the hot spot, $\alpha=0.80$ if the detail is classified as $\mathrm{C} 1$ with stress parallel to the weld at the hot spot, $\alpha=0.72$ if the detail is classified as $\mathrm{C}$ with stress parallel to the weld at the hot spot, and $\Delta \sigma_{1}$ and $\Delta \sigma_{2}$ are principal stress ranges. Principal stress ranges can be calculated as

$$
\begin{aligned}
& \Delta \sigma_{1}=\frac{\Delta \sigma_{x}}{2}+\frac{1}{2} \sqrt{\Delta \sigma_{x}^{2}+4 \Delta \tau_{x y}^{2}} \\
& \Delta \sigma_{2}=\frac{\Delta \sigma_{x}}{2}-\frac{1}{2} \sqrt{\Delta \sigma_{x}^{2}+4 \Delta \tau_{x y}^{2}}
\end{aligned}
$$

According to Eurocode 3, in the case of the combined normal and shear stress ranges, the fatigue analysis should be verified by the following equation

$$
\left(\frac{\gamma_{\mathrm{Ff}} \Delta \sigma_{\mathrm{E}, 2}}{\Delta \sigma_{\mathrm{C}} / \gamma_{\mathrm{Mf}}}\right)^{3}+\left(\frac{\gamma_{\mathrm{Ff}} \Delta \tau_{\mathrm{E}, 2}}{\Delta \tau_{\mathrm{C}} / \gamma_{\mathrm{Mf}}}\right)^{5} \leq 1.0
$$


where $\gamma_{\mathrm{Ff}}$ is the partial factor for equivalent constant amplitude stress ranges $\Delta \sigma_{\mathrm{E}, 2}$ and $\Delta \tau_{\mathrm{E}, 2}$ $\left(\gamma_{\mathrm{Ff}}=1\right.$ ), and $\gamma_{\mathrm{Mf}}$ is the partial factor for fatigue strength $\Delta \sigma_{\mathrm{C}}$ and $\Delta \tau_{\mathrm{C}}$ related to 2 million cycles $\left(\gamma_{\mathrm{Mf}}=1\right)$. Eq. 9 can be rewritten according to [22]

$D_{\sigma}+D_{\tau} \leq 1$

where $D_{\sigma}$ and $D_{\tau}$ represent fatigue damage caused by the normal and shear stress ranges, respectively. They can be expressed as

$$
\begin{aligned}
& D_{\sigma}=\left(\frac{\Delta \sigma_{\mathrm{E}, 2}}{\Delta \sigma_{\mathrm{C}}}\right)^{3} \\
& D_{\tau}=\left(\frac{\Delta \tau_{\mathrm{E}, 2}}{\Delta \tau_{\mathrm{C}}}\right)^{5}
\end{aligned}
$$

The fatigue life $N_{\mathrm{f}}$ can be expressed as

$\frac{N_{\mathrm{f}}}{N_{\sigma}}+\frac{N_{\mathrm{f}}}{N_{\tau}}=1 \Rightarrow N_{\mathrm{f}}=\frac{N_{\sigma} N_{\tau}}{N_{\sigma}+N_{\tau}} \quad$ and $N_{\mathrm{f}}<10^{7}$ (cycles)

where $N_{\sigma}$ and $N_{\tau}$ are the fatigue lives subjected to the normal and shear stress ranges, respectively, and $N_{\mathrm{f}}$ is the fatigue life subjected to the combined normal and shear stress ranges. According to Eurocode 3, the fatigue lives $N_{\sigma}$ and $N_{\tau}$ can be respectively expressed as

$$
\begin{aligned}
& \Delta \sigma_{\mathrm{E}, 2}^{3} N_{\sigma}=2 \times 10^{6} \Delta \sigma_{\mathrm{C}}^{3} \Rightarrow N_{\sigma}=2 \times 10^{6} \frac{\Delta \sigma_{\mathrm{C}}^{3}}{\Delta \sigma_{\mathrm{E}, 2}^{3}} \\
& \Delta \tau_{\mathrm{E}, 2}^{5} N_{\tau}=2 \times 10^{6} \Delta \tau_{\mathrm{C}}^{5} \Rightarrow N_{\tau}=2 \times 10^{6} \frac{\Delta \tau_{\mathrm{C}}^{5}}{\Delta \tau_{\mathrm{E}, 2}^{5}}
\end{aligned}
$$

Therefore, Eq. 13 can be rewritten as

$$
N_{\mathrm{f}}=\frac{2 \times 10^{6} \cdot\left(\frac{\Delta \sigma_{\mathrm{C}}}{\Delta \sigma_{\mathrm{E}, 2}}\right)^{3} \cdot\left(\frac{\Delta \tau_{\mathrm{C}}}{\Delta \tau_{\mathrm{E}, 2}}\right)^{5}}{\left(\frac{\Delta \sigma_{\mathrm{C}}}{\Delta \sigma_{\mathrm{E}, 2}}\right)^{3}+\left(\frac{\Delta \tau_{\mathrm{C}}}{\Delta \tau_{\mathrm{E}, 2}}\right)^{5}} \text { and } N_{\mathrm{f}}<10^{7} \text { (cycles) }
$$

For the evaluation of the biaxial stress states with the combined normal and shear stress ranges under constant amplitude proportional loading according to IIW, the following relationship should be met based on the Gough-Pollard criterion [35] 


$$
\left(\frac{\Delta \sigma_{\mathrm{S}, \mathrm{d}}}{\Delta \sigma_{\mathrm{R}, \mathrm{d}}}\right)^{2}+\left(\frac{\Delta \tau_{\mathrm{S}, \mathrm{d}}}{\Delta \tau_{\mathrm{R}, \mathrm{d}}}\right)^{2} \leq 1.0
$$

where $\Delta \sigma_{\mathrm{R}, \mathrm{d}}$ and $\Delta \tau_{\mathrm{R}, \mathrm{d}}$ are the design resistances of the normal and shear stress ranges at 2 million cycles, respectively, and $\Delta \sigma_{\mathrm{S}, \mathrm{d}}$ and $\Delta \tau_{\mathrm{S}, \mathrm{d}}$ are the design values of the normal and shear stress ranges, respectively. Eq. 17 can be rewritten based on Eqs. 11 and 12

$D_{\sigma}^{2 / 3}+D_{\tau}^{2 / 5} \leq 1$

The fatigue life $N_{\mathrm{f}}$ can be expressed as

$$
\left(\frac{N_{\mathrm{f}}}{N_{\sigma}}\right)^{2 / 3}+\left(\frac{N_{\mathrm{f}}}{N_{\tau}}\right)^{2 / 5}=1 \quad \text { and } N_{\mathrm{f}}<10^{7}(\text { cycle })
$$

where

$$
\begin{gathered}
\Delta \sigma_{\mathrm{S}, \mathrm{d}}^{3} N_{\sigma}=2 \times 10^{6} \Delta \sigma_{\mathrm{R}, \mathrm{d}}^{3} \Rightarrow N_{\sigma}=2 \times 10^{6} \frac{\Delta \sigma_{\mathrm{R}, \mathrm{d}}^{3}}{\Delta \sigma_{\mathrm{S}, \mathrm{d}}^{3}} \\
\Delta \tau_{\mathrm{S}, \mathrm{d}}^{5} N_{\tau}=2 \times 10^{6} \Delta \tau_{\mathrm{R}, \mathrm{d}}^{5} \Rightarrow N_{\tau}=2 \times 10^{6} \frac{\Delta \tau_{\mathrm{R}, \mathrm{d}}^{5}}{\Delta \tau_{\mathrm{S}, \mathrm{d}}^{5}}
\end{gathered}
$$

Given an initial value, the fatigue life can be obtained by iterative numerical methods using Eq. 19.

According to hot spot stress results, the parameters used to calculate the fatigue life are listed in Table 4. Based on welded details in fatigue design specifications, the fatigue design curves of FAT100 (a stress range of $100 \mathrm{MPa}$ at 2 million cycles with a survival probability $P_{\mathrm{s}}=97.7 \%$ ) and FAT120 for the hot spot normal stress range and shear stress range should be taken according to Eurocode 3 and IIW, respectively. The fatigue design curves of FAT100 and FAT90 are used by the equivalent stress range method and DNV, respectively. The fatigue life prediction results of full penetration load-carrying fillet cruciform welded joints at various inclined angles by using the equivalent stress range method, DNV, Eurocode 3, and IIW are summarized in Table 5. A comparison of the fatigue life prediction and experimental results and the relationship between fatigue life and inclined angle are shown in Figures 10 and 11. 
Table 4. Calculated Parameters (MPa)

\begin{tabular}{ccccc}
\hline$\theta$ & $\Delta \sigma_{\text {eqv }}$ & $\Delta \sigma_{\text {eff }}$ & $\Delta \sigma_{\mathrm{E}, 2}=\Delta \sigma_{\mathrm{S}, \mathrm{d}}$ & $\Delta \tau_{\mathrm{E}, 2}=\Delta \tau_{\mathrm{S}, \mathrm{d}}$ \\
\hline $0^{\circ}$ & 165.89 & 160.99 & 165.89 & - \\
$15^{\circ}$ & 161.58 & 155.33 & 156.54 & 44.62 \\
$30^{\circ}$ & 146.56 & 140.00 & 130.99 & 76.59 \\
$45^{\circ}$ & 127.24 & 124.57 & 95.45 & 91.43 \\
\hline
\end{tabular}

Table 5. Fatigue Life Prediction Results (cycles)

\begin{tabular}{ccccc}
\hline$\theta$ & $\begin{array}{c}\text { Equivalent stress } \\
\text { range method }\end{array}$ & DNV & Eurocode 3 & IIW \\
\hline $0^{\circ}$ & $4.38 \times 10^{5}$ & $3.49 \times 10^{5}$ & $4.38 \times 10^{5}$ & $4.38 \times 10^{5}$ \\
$15^{\circ}$ & $4.74 \times 10^{5}$ & $3.89 \times 10^{5}$ & $5.20 \times 10^{5}$ & $4.62 \times 10^{5}$ \\
$30^{\circ}$ & $6.35 \times 10^{5}$ & $5.31 \times 10^{5}$ & $8.50 \times 10^{5}$ & $5.80 \times 10^{5}$ \\
$45^{\circ}$ & $9.71 \times 10^{5}$ & $7.54 \times 10^{5}$ & $1.78 \times 10^{6}$ & $9.75 \times 10^{5}$ \\
\hline
\end{tabular}

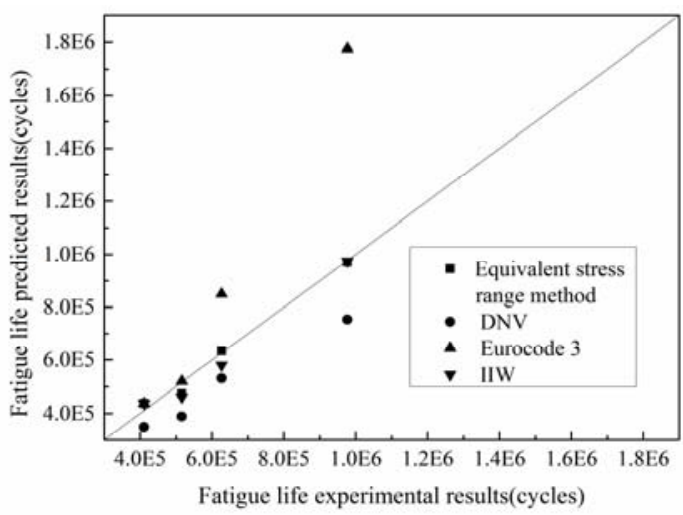

Figure 10. A Comparison of the Fatigue Life Prediction and Experimental Results

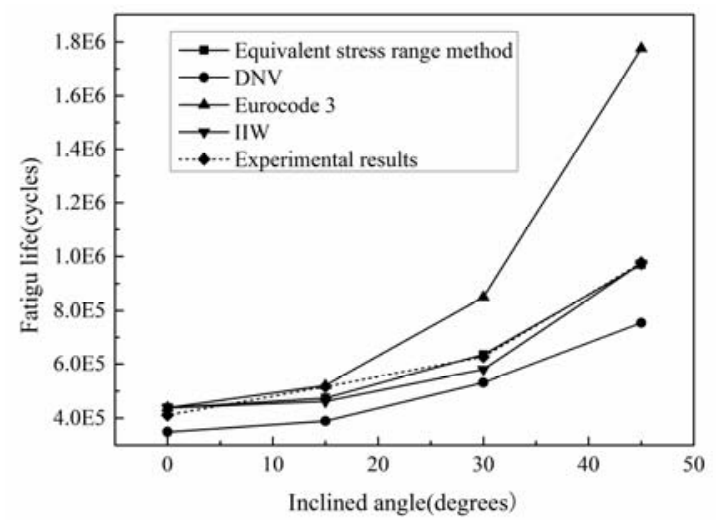

Figure 11. The Relationship Between Fatigue Life and Inclined Angle

It can be seen from Table 5 and Figures 10-11 that the fatigue life increases with an increase in the inclined angle due to a decrease in the normal stress range perpendicular to the weld. Fatigue life test results of welded joints with $\theta=15^{\circ}, 30^{\circ}$, and $45^{\circ}$ are $1.26,1.52$, and 2.38 times larger than that at $\theta=0^{\circ}$, respectively. Because the fatigue resistance value of the hot spot stress curve is conservative according to $\mathrm{DNV}$, the fatigue life prediction results are less than the other three methods and approximately 0.8 times that of fatigue life test results. When the inclined angle $\theta$ is less than or equal to $15^{\circ}$, the fatigue life values predicted by the equivalent stress range method, Eurocode 3, and IIW have no significant difference and are close to experimental results. The fatigue life results predicted by Eurocode 3 are $35.5 \%$ and $81.8 \%$ larger than those of the experimental results at $\theta=30^{\circ}$ and $45^{\circ}$, respectively. The equivalent stress range method and IIW are in good agreement with the fatigue test data and the maximum relative error is only $-10.5 \%$. However, it is easier and more convenient to calculate the fatigue life using the equivalent stress 
range method compared with IIW. Therefore, the equivalent stress range method is recommended to assess the fatigue life of inclined welded joints subjected to combined tension and shear stresses. The fatigue design curve of FAT100 is a better choice than FAT90.

\section{CONCLUSIONS}

Fatigue life assessment of inclined welded joints in steel bridges subjected to a combination of normal and shear stresses using the equivalent stress range method, DNV, Eurocode 3, and IIW are investigated in this study. Fatigue tests on cruciform welded joints with full penetration load-carrying welds inclined to the direction of the uniaxial cyclic loading are carried out. Hot spot normal and shear stress ranges are obtained with a linear extrapolation, and a sensitivity analysis is conducted to determine the appropriate mesh size. Based on the numerical analysis and fatigue test results, the following conclusions can be drawn.

(1) Fatigue failure in all of the specimens is initiated at the weld toe but propagates in different directions. There are two cracking types: (a) cracking along the weld; (b) cracking perpendicular to the direction of the applied load. When the inclined angle is $0^{\circ}$ or $15^{\circ}$, the cracks propagate along the weld. However, when the inclined angle is $30^{\circ}$ or $45^{\circ}$, the cracks propagate along the perpendicular direction of the applied load.

(2) With an increase in the inclined angle, the hot spot normal stress range decreases, while the hot spot shear stress range increases. The hot spot stress range increases with an increase in the mesh size. The mesh size used in IIW is more sensitive than that used in DNV due to the difference in linear extrapolation rules. When the minimum mesh size is less than $0.1 t$, the effect of the mesh size on the hot spot stress range is fairly small. Fatigue evaluation techniques for complex welded joints in steel bridges should be based on accurate stress calculations determined by a mesh sensitivity analysis.

(3) The fatigue life increases with an increase in the inclined angle due to a decrease in the normal stress range perpendicular to the weld. The fatigue life test results of welded joints with $\theta=15^{\circ}$, $30^{\circ}$, and $45^{\circ}$ are $1.26,1.52$, and 2.38 times larger than that at $\theta=0^{\circ}$, respectively. The design recommendations by Eurocode 3 tend to overpredict the fatigue life at large inclination angles. The FAT90 used by DNV is more conservative than the FAT100 recommended by Eurocode 3 and IIW, so that the fatigue life is underestimated. The equivalent stress range method and IIW are found to be in good agreement with the fatigue test data. However, the equivalent stress rang method is recommended to assess the fatigue life of inclined welded joints subjected to a combination of normal and shear stresses due to the ease of implementation and low computational cost. The fatigue design curve of FAT100 in Eurocode 3 and IIW is appropriate for the equivalent stress range method.

\section{ACKNOWLEDGEMENTS}

This research is supported by National Natural Science Foundation of China (Grant Nos. 51708305, 51378430, and 51378431), Zhejiang Provincial Natural Science Foundation of China (Grant Nos. LQ17E080005, LY15E080012, and LY17E080007), and K. C. Wong Magna Fund in Ningbo University. 


\section{REFERENCES}

[1] Fricke, W., "Fatigue Analysis of Welded Joints: State of Development", Marine Structures, 2003, Vol. 16, No. 3, pp. 185-200.

[2] Maddox, S.J., "Review of Fatigue Assessment Procedures for Welded Aluminium Structures", International Journal of Fatigue, 2003, Vol. 25, No. 12, pp. 1359-1378.

[3] Park, W. and Miki, C., "Fatigue Assessment of Large-size Welded Joints based on the Effective Notch Stress Approach", International Journal of Fatigue, 2008, Vol. 30, No. 9, pp. 1556-1568.

[4] Van Wingerde, A.M., Packer, J.A. and Wardenier, J., "Criteria for the Fatigue Assessment of Hollow Structural Section Connections", Journal of Constructional Steel Research, 1995, Vol. 35, No. 1, pp. 71-115.

[5] EN 1993-1-9, "Eurocode 3: Design of Steel Structures Part 1-9: Fatigue", European Committee for Standardization, 2005.

[6] Hobbacher, A., "Recommendations for Fatigue Design of Welded Joints and Components", the International Institute of Welding, 2007.

[7] Det Norske, Veritas, "Fatigue Design of Offshore Steel Structures", Det Norske Veritas, 2010.

[8] Dong, P., "A Structural Stress Definition and Numerical Implementation for Fatigue Analysis of Welded Joints", International Journal of Fatigue, 2001, Vol. 23, No. 10, pp. 865-876.

[9] Fricke, W., "Recommended Hot-spot Analysis Procedure for Structural Details of Ships and FPSOs based on Round-robin FE Analyses", International Journal of Offshore and Polar Engineering, 2002, Vol. 12, No. 1, pp. 40-47.

[10] Xiao, Z.G. and Yamada, K., "A Method of Determining Geometric Stress for Fatigue Strength Evaluation of Steel Welded Joints", International Journal of Fatigue, 2004, Vol. 26, No. 12, pp. 1277-1293.

[11] Doerk, O., Fricke, W. and Weissenborn, C., "Comparison of Different Calculation Methods for Structural Stresses at Welded Joints", International Journal of Fatigue, 2003, Vol. 25, No. 5, pp. 359-369.

[12] Lee, J., Seo, J. and Kim, M., et al., "Comparison of Hot Spot Stress Evaluation Methods for Welded Structures", International Journal of Naval Architecture and Ocean Engineering, 2010, Vol. 2, No. 4, pp. 200-210.

[13] Liu, R., Liu, Y.Q. and Ji, B.H., et al., "Hot Spot Stress Analysis on Rib-deck Welded Joint in Orthotropic Steel Decks", Journal of Constructional Steel Research, 2014, Vol. 97, pp. $1-9$.

[14] Oh, D.J., Lee, J.M. and Kim, M.H., "Fatigue Strength Assessment of Invar Alloy Weld Joints using the Notch Stress approach", Engineering Failure Analysis, 2014, Vol. 42, pp. 87-99.

[15] Barsoum, Z., Khurshid, M. and Barsoum, I., "Fatigue Strength Evaluation of Friction Stir Welded Aluminium Joints using the Nominal and Notch Stress Concepts", Materials \& Design, 2012, Vol. 41, pp. 231-238.

[16] Radaj, D., Sonsino, C.M. and Fricke, W., "Recent Developments in Local Concepts of Fatigue Assessment of Welded Joints", International Journal of Fatigue, 2009, Vol. 31, No. 1, pp. 2-11.

[17] Sonsino, C.M., Fricke, W. and De Bruyne, F., et al., "Notch Stress Concepts for the Fatigue Assessment of Welded Joints-Background and Applications", International Journal of Fatigue, 2012, Vol. 34, No. 1, pp. 2-16.

[18] Connor, R.J. and Fisher, J.W., "Consistent Approach to Calculating Stresses for Fatigue Design of Welded Rib-to-web Connections in Steel Orthotropic Bridge Decks", Journal of Bridge Engineering, 2006, Vol. 11, No. 5, pp. 517-525. 
[19] Wang, Z.Y. and Wang, Q.Y., "Fatigue Assessment of Welds Joining Corrugated Steel Webs to Flange Plates", Engineering Structures, 2014, Vol. 73, pp. 1-12.

[20] Susmel, L., Sonsino, C.M. and Tovo, R., "Accuracy of the Modified Wöhler Curve Method Applied along with the $r_{\mathrm{ref}}=1 \mathrm{~mm}$ concept in Estimating Lifetime of Welded Joints subjected to Multiaxial Fatigue Loading", International Journal of Fatigue, 2011, Vol. 33, No. 8, pp. 1075-1091.

[21] Kim, I.T. and Yamada, K., "Fatigue Life Evaluation of Welded Joints under Combined Normal and Shear Stress Cycles", International Journal of Fatigue, 2005, Vol. 27, No. 6, pp. 695-701.

[22] Lotsberg, I., "Assessment of Design Criteria for Fatigue Cracking from Weld Toes subjected to Proportional Loading", Ships and Offshore Structures, 2009, Vol. 4, No. 2, pp. 175-187.

[23] Bäckström, M., "Multiaxial Fatigue Life Assessment of Welds based on Nominal and Hot Spot Stresses", Lappeenranta: Lappeenranta University of Technology, 2003.

[24] SFS 2378, "Load Capacity of Welded Joints in Fatigue Loaded Steel Structures", Federation of the Finnish Metal and Engineering Industries, 1992.

[25] Kainuma, S., Katsuki, H. and Iwai, I., et al., "Evaluation of Fatigue Strength of Friction Stir Butt-welded Aluminum Alloy Joints inclined to Applied Cyclic Stress", International Journal of Fatigue, 2008, Vol. 30, No. 5, pp. 870-876.

[26] Jen, Y., Chang, L. and Fang, C., "Assessing the Fatigue Life of Butt-welded Joints under Oblique Loading by using Local Approaches", International Journal of Fatigue, 2008, Vol. 30, No. 4, pp. 603-613.

[27] Susmel, L., "Nominal Stresses and Modified Wöhler Curve Method to Perform the Fatigue Assessment of Uniaxially Loaded Inclined Welds", Proceedings of the Institution of Mechanical Engineers, Part C: Journal of Mechanical Engineering Science, 2014, pp.1-10.

[28] Khurshid, M., Barsoum, Z. and Barsoum, I., et al., "The Multiaxial Weld Root Fatigue of Butt Welded Joints subjected to Uniaxial Loading", Fatigue \& Fracture of Engineering Materials \& Structures, 2016, pp. 1-18.

[29] GB/T 714, "Structural Steel for Bridge", Standardization Administration of the People's Republic of China, 2015.

[30] Fatemi, A. and Socie, D.F., "A Critical Plane Approach to Multiaxial Fatigue Damage Including out-of-Phase Loading" Fatigue \& Fracture of Engineering Materials \& Structures, 1988, Vol. 11, No. 3, pp. 149-165.

[31] Bäckström, M. and Marquis, G., "A Review of Multiaxial Fatigue of Weldments: Experimental Results, Design Code and Critical Plane Approaches", Fatigue \& Fracture of Engineering Materials \& Structures, 2001, Vol. 24, No. 5, pp. 279-291.

[32] ANSYS Inc., "ANSYS Mechanical User's Guide", ANSYS Inc., 2012.

[33] Kim, I.T. and Yamada, K., "Fatigue Behaviour of Fillet Welded Joints Inclined to a Uniaxial Load", The International Institute of Welding, 2004.

[34] Lotsberg, I., "Fatigue Design Criteria as Function of the Principal Stress Direction Relative to the Weld Toe", Proceedings of the ASME 27th International Conference on Offshore Mechanics and Arctic Engineering, Estoril, Portugal, 2008.

[35] Gough, H.J. and Pollard, H.V., "The Strength of Metals under Combined Alternating Stresses", Proceedings of the Institution of Mechanical Engineers, 1935, Vol. 131, No. 1, pp. 3-103. 